\title{
MENTIRAS DESBOCADAS, MEDIOS DE COMUNICACIÓN, INTERNET Y MARKETING VIRAL
}

\section{THE RUNAWAY LIES, MEDIA, INTERNET AND VIRAL \\ ADVERTISING}

\begin{abstract}
AUTORES
Susana Torrado Morales: Facultad de Comunicación y Documentación. Universidad de Murcia. Murcia (España).

storrado@um.es
\end{abstract}

César San Nicolás Romera: Facultad de Comunicación y Documentación. Universidad de Murcia. Murcia (España).

cnicolas@um.es

Beatriz Gómez Baceiredo: Facultad de Comunicación. Universidad de Navarra. Pamplona (España) bgomezb@unav.es

\section{RESUMEN}

La necesidad de ser los más rápidos en dar las noticias y el uso inadecuado de Internet como fuente de documentación han derivado en los últimos años en un gran número de errores en los medios de comunicación, no sólo en España, sino también en el resto del mundo. Sucumbir a la velocidad deriva en no cotejar las fuentes, ambas cosas están siendo explotadas por el sector publicitario. El marketing viral se aprovecha de la red al lanzar un "engaño" a los espectadores, oyentes o lectores bajo la apariencia de noticias que dan el salto de forma automática a los medios de comunicación y que, finalmente, terminan revelándose como propuestas publicitarias, cuya función principal es vender un producto o propagar la adhesión a una determinada marca. El objetivo de este artículo es reflexionar sobre cómo la velocidad interviene decididamente en la conformación de un universo de informaciones, desinformaciones y nuevas propuestas 
persuasivas, ejemplificando esas "historias de velocidad en los medios" a través del análisis de algunos casos ocurridos en España en los últimos años.

\section{PALABRAS CLAVE}

Marketing viral - Medios de comunicación - Publicidad- Engaño - Velocidad Astroturfing

\section{ABSTRACT}

The objective of this paper is therefore to reflect on how speed intrudes decisively in composition in the world of information, of disinformation and of its new persuasive purposes, by exemplifying these "Stories of Speed in the Media" by way of the analysis of some occurrences in Spain in recent years. Among the most famous cases we were able to find were false news reports about politics (the theft of the parliamentary seat of the prime minister, Rodríguez Zapatero) or religious or social customs (the coverage of a musical video created by a supposedly Catholic group "The Association of the Newly Reborn" - advocating virginity until marriage). The consequences of some of these cases, born since the era of the world of publicity as viral marketing campaigns can be turned against their own creators as in the case of the campaign "estosololoarreglamosentretodos.org" and the counter-campaign which it gave rise to in the Internet.

\section{KEY WORDS}

Viral marketing - Media - Advertising - Fake - Speed - Astroturfing

\section{ÍNDICE}

$\boldsymbol{n}$ 1. INTRODUCCIÓN

$\boldsymbol{\sim}$ 2. VELOCIDAD Y MEDIOS DE COMUNICACIÓN

$\sim$ 3. ERRORES, MENTIRAS DESBOCADAS Y PUBLICIDAD

$\approx$ 4. REDES INFECTADAS, "SNEEZERS" Y MARKETING VIRAL

^ 5. MENTIRAS DESBOCADAS VERSUS NOTICIAS EN ESPAÑA

a 6. CONCLUSIONES 


\section{BIBLIOGRAFÍA}

\section{INTRODUCCIÓN}

El martes 17 de marzo de 2010 a las 12 de la noche, la agencia de noticias española EFE distribuía la foto de un supuesto terrorista de ETA como uno de los miembros del comando terrorista que había asesinado a un policía en Francia unos días antes. Un nombre con unos apellidos muy comunes en España y sus antecedentes de militancia en un partido de izquierdas le habían convertido por sorpresa en un peligro en una sociedad marcada por el terrorismo nacionalista e islamista. Una simple búsqueda en Google y la necesidad de los mass media por mostrar noticias a toda velocidad habían transformado a un joven anónimo en "terrorista por un día". Esa velocidad y el uso inadecuado de Internet como fuente de documentación han derivado en los últimos años en un gran número de errores en los medios de comunicación, no sólo en España, sino también en el resto del mundo.

La necesidad de ser los más rápidos en dar las noticias sin cotejar las fuentes está siendo explotada por el sector publicitario. El marketing viral se aprovecha de la red al lanzar un "engaño" a los espectadores, oyentes o lectores bajo la apariencia de noticias que dan el salto de forma automática a los medios de comunicación y que, finalmente, terminan revelándose como propuestas publicitarias, cuya función principal es vender un producto o propagar la adhesión a una determinada marca. El uso de las imágenes secuenciadas, editadas y cuidadosamente manipuladas (fake) nos habla también de cómo la esfera de la tecnología interviene decididamente a la hora de aprovechar la supuesta legitimidad de dichas imágenes, creando un nuevo universo comunicativo regido por la fuerza del audiovisual en su versión más perversa.

Los medios informativos luchan desesperadamente por mantener la atención de su audiencia a partir de lo novedoso, lo extraordinario, y tienen que hacerlo antes que nadie 
para ganar protagonismo y diferenciarse de la competencia. Los medios de comunicación abandonan su papel de protagonistas de la sociedad de la información para adoptar el papel de luchadores en la Economía de la Atención, una atención que "is focused mental engagement on a particular item of information. Items come into our awareness, we attend to a particular item, and then we decide whether to act" (Davenport \& Beck 2001, p. 20). Se considera la atención humana como un bien escaso y necesario a la hora de conocer cómo gestionar la información.

Los hechos se conocen casi al instante, por eso hay que ir más allá: las imágenes más impactantes, las últimas sospechas policiales, los testigos que se convierten en productores de la información con sus vídeos y declaraciones. Esta urgencia no sólo provoca errores a la hora de confirmar la autenticidad de los datos o la veracidad de las fuentes, sino que hace a los medios mucho más vulnerables a los intereses comerciales o políticos de las agencias de publicidad y de los gabinetes de comunicación institucional. Porque en un momento en que los medios viven atosigados por la cantidad e inmediatez de la información, no tienen tiempo para construir lo que la audiencia de veras quiere: las historias, los relatos, conocer a los protagonistas de esas acciones extraordinarias. Como afirma Núñez, “La globalidad, virtualidad y aceleración han empobrecido hasta tal punto las clásicas fuentes de materiales narrativos que tenemos que buscar otras para encontrar relatos ricos en sentido vital" (Núñez, 2007: 53). Los publicistas y relaciones públicas no tiene más que construir una historia, con los protagonistas muy bien elegidos y que satisfaga la necesidad de los lectores de encontrar en ella a héroes, mártires y villanos.

\section{VELOCIDAD Y MEDIOS DE COMUNICACIÓN}

La realidad de los mass media vive instalada en un sistema tecnológico avanzado, donde los flujos de información y las redes intervienen activamente para conformar un mundo regido por el concepto de velocidad o, lo que es lo mismo, por la inmediatez. Lo mediático 
es, de alguna manera, lo inmediato y dicha identificación conceptual entraña un uso estratégico del tiempo como factor dinamizador de una sociedad en red capaz de crear un mercado de contenidos informativos, persuasivos y lúdicos para nutrir sus propias demandas de conocimiento, entretenimiento y autosatisfacción.

Basándonos en las aportaciones de Paul Virilio - sobre todo las vertidas en sus obras $\mathrm{La}$ machine de vision, L'art du moteur; Cybermonde, la politique du pire y La bombe informatique podemos vislumbrar cómo la puesta en práctica del concepto "tiempo real" nos aleja de la noción de tiempo histórico (local), para plantear un único "tiempo mundial" (global). Las posibilidades de interacción comunicativa, vinculadas al desarrollo de las tecnologías de la información, nos trasladan a un tiempo único mundializado donde se instala una inmediatez en red canalizada a través de la velocidad como principio. Tal y como nos recuerda Virilio en su obra Cibermundo, la política de lo peor:

Si se da una definición filosófica de la velocidad, se puede decir que no es un fenómeno, sino la relación entre los fenómenos. Dicho de otro modo, la relatividad en sí misma. Se puede incluso llegar más lejos y decir que la velocidad es un medio. No es simplemente un problema de tiempo entre dos puntos, es un medio que está provocado por el vehículo. Este vehículo puede ser metabólico como en el caso de la caballería en la historia, o técnico como el papel del navío en la conquista marítima, o los ferrocarriles o los aviones transatlánticos, y condiciona las sociedades. (Virilio, 1997: 16)

Dicho vehículo, puede incluso llegar a ser cibernético como en el caso de Internet que se convierte en una potente "máquina de visión" y, a la postre, en un elemento catalizador para la nueva caracterización de los medios de comunicación en el contexto de una sociedad digital/sociedad red, como afirmara el sociólogo Manuel Castells, donde comunicación/velocidad/poder establecen un trinomio capaz de modificar las rutinas 
profesionales, y fundamentalmente la manera de percibir las relaciones entre los usuarios, los productos y sus destinatarios.

Las razones fundamentales de esta transformación y de su extensión al papel comunicativo de los medios, no sólo informativos sino persuasivos, hay que buscarlas en las raíces de la revolución de los transportes del siglo XIX, vinculada con la revolución, primero de las transmisiones y, más tarde, de las tecnologías de lo virtual, propias del siglo XX. La revolución de los transportes permitió una aceleración capaz de acortar las distancias físicas y, por extensión, las distancias productivas. La revolución informática y el desarrollo de Internet han posibilitado una nueva maniobra de aceleración que permite acortar las distancias entre los sujetos y, ante todo, entre los productores de contenidos y los consumidores de dichos contenidos.

En ese contexto de inmediatez, los productos de la comunicación aparecen insertos en una lógica de producción, circulación y consumo que evidencian su carácter, antes que social, cultural. El poder de la cultura ha ganado terreno a una visión del mundo estructurado socialmente. Como bien nos recuerda Alain Touraine en Un Nouveau paradigme,

(...) el análisis de la realidad social en términos propiamente sociales respondía al universo político que nos dominó durante un largo período, y que había comenzado con Maquiavelo y había durado hasta Tocqueville, pasando por Hobbes y Rousseau. La crisis y la descomposición del paradigma social de la vida social han creado un caos en el que han penetrado la violencia, la guerra y la dominación de los mercados que escapan a toda regulación social, pero también la obsesión de los comunitarismos por su identidad (Touraine, 2005: 29).

La presencia hegemónica de estas nuevas políticas formales nos habla de la importancia, en este nuevo paradigma, de la cultura como elemento motor. El sujeto parece luchar 
contra cualquier forma de corsé social y se ve sometido a nuevos parámetros de control asentados sobre una conciencia mediática que da sentido a su experiencia. Esa conciencia mediática es la que crea una visión de la realidad desenfocada capaz de asimilar cualquier signo o símbolo de la cultura y de la contracultura. Se trata de una "teoría de la apropiación" de los símbolos donde cualquier elemento de identificación es desposeído de su contenido original, recargado y comercializado como un nuevo producto resultante. El único requerimiento es que el símbolo, desprovisto de su contenido original, posea fecha de caducidad casi inmediata, sea rápido y fácilmente consumible, finamente envasado para que se perciba su contenido. Consumir es destruir y cualquier elemento que acelere esa reacción facilitará que esa propia inercia vuelva a reestablecer el circuito produccióncirculación-consumo.

Ante esa realidad, es preciso considerar que los medios imponen ese mismo rigor a la hora de demandar contenidos editables y programables. Un rigor basado en la velocidad que genera errores y extrañas apropiaciones simbólicas. Como afirmaba el apocalíptico Jean Baudrillard, es el resultado de vivir en un contexto semiúrgico, esto es, en un ámbito de manipulación generalizada de los signos de la vida cotidiana. Es la sustitución de la necesidad de una lógica de búsqueda de la proporcionalidad, la simetría y lo correcto por la necesidad de abrazar lo emocional y lo extremoso; es la sustitución de la información por la polémica, de la argumentación por el fenómeno del fanatismo y de la realidad por la apariencia.

\section{ERRORES, MENTIRAS DESBOCADAS Y PUBLICIDAD}

La institucionalización de nuestra sociedad-red diseminada en micro-colectivos de redes sociales (Facebook, Twitter, etc.) ha hecho que una nueva lógica se instale dentro de las manifestaciones de la comunicación persuasiva. Hoy en día cualquier persona puede dar de alta un "falso perfil" de alguna celebrity y difundir una "falsa noticia" vinculada con su 
vida privada o su vida profesional (un célebre futbolista que anuncia su presunto fichaje inminente por un equipo rival, la presencia en la red de un supuesto vídeo de una actriz en escenas íntimas, etc.). Los sujetos en red actúan como propagadores de mistakes y de fakes. Intentando obviar el carácter legal/ilegal de lo que moralmente se nos presenta como una invasión evidente en el honor y la intimidad de las personas; desde nuestro punto de vista de investigadores del fenómeno de la comunicación, este tipo de manifestaciones dejan entrever cómo las condiciones de relación de los usuarios y los medios se modifican hasta el punto de establecer una dimensión diferente de relación entre aquellos y estos. El usuario es transformado aparentemente en un sujeto activo, en un agente al servicio del propósito comunicativo/persuasivo del medio, aunque el resultado venga precedido del lanzamiento a la esfera pública de un acontecimiento impreciso (mistake) o de una ocurrencia informativo/persuasiva manipulada y falseada pero con dosis de verosimilitud (fake). El uso del error es involuntario (supuestamente), mientras que la utilización del fake es intencionado. Tanto unos como otros, están regidos por la velocidad de generación de ocurrencias mediáticas y por la intervención de dicha velocidad sobre el carácter inmediato del medio, esto es, son fenómenos similares a las "instant movies", relatos creados a gran velocidad, de forma inmediata - previa elaboración- a la noticia, evento o acontecimiento.

Si este fenómeno se hace patente en el escenario de la información periodística con la aparición del "periodismo ciudadano" (usuarios que actúan como corresponsales del medio elaborando o suministrando información, fundamentalmente audiovisual, a través de blogs, redes sociales, etc.), en el ámbito de la publicidad, las fórmulas alcanzan unos niveles de especificidad propios de los fines estratégicos de cada soporte y acción comunicativa. Así surge uno de los fenómenos publicitarios que en los últimos años obtiene una mejor ratio entre eficacia/inversión: nos referimos al marketing/publicidad viral. 
Si introducimos dicho término en inglés en el buscador google, automáticamente aparecen 6.680.000 resultados. A poco que exploremos acerca de en qué consiste dicha práctica, llegaremos a una definición más o menos aceptada: es una estrategia comercial basada en crear publicidad que se propague a sí misma. Como en la mayoría de estas nuevas prácticas publicitarias, la noción de velocidad e inmediatez de producción, circulación y consumo borra cualquier huella sobre su origen. No podemos establecer cuándo nace o en qué momento empieza a utilizarse. No obstante, sí podemos constatar su eficacia comunicativa, por el uso específico en determinadas campañas publicitarias que han dado el salto al entorno de los medios de comunicación, convirtiéndose en acontecimientos noticiables, gracias al componente de artificiosidad y efectismo de las mismas.

\section{REDES INFECTADAS, “SNEEZERS" Y MARKETING VIRAL}

Douglas Rushkoff, en 1994, en su obra Media Virus: hidden agendas in popular culture consideraba que los "susceptible users" (interesados en la publicidad corporativa enviada a través de servicios gratuitos de correo electrónico, como Yahoo o Hotmail) se convertían en "infected users" al dar de alta una cuenta propia de correo. Todos los usuarios a los que el "usuario infectado" reenviaba el mensaje comenzaban a formar parte de esa comunidad de usuarios infectados ${ }^{1}$. De los comienzos de este fenómeno, con los forwards del correo electrónico, se ha pasado a múltiples y variadas estrategias como enlaces a páginas web, flash, blogs... con un objetivo común: "la creación de una corriente epidemiológica en donde el mensaje es el centro de acción" (Del Pino, 2007: 68).

Según Godin (2001) existen dos tipos de emisores/receptores dentro de la cadena bocaoreja: “sneezer promiscuo" y "sneezer poderoso". Ambos, al "estornudar" adoptan las ideas

\footnotetext{
${ }^{1}$ En 1996, Hotmail aumentó su número de clientes (12 millones en 18 meses), después de haber incluido al final de sus mails el footer "Consigue tu propio correo electrónico gratuito en Hotmail.com".
} 
y participan activamente difundiéndolas, participando en el proceso de comunicación de forma voluntaria, activa y espontánea. Los primeros no están valorados como líderes de opinión pero los segundos han originado cambios en el mercado, al introducir al resto de infectados en una nueva idea-virus.

Parafraseando a Mar Heras, así como algunas enfermedades graves son auto-inmunes, el marketing viral confunde nuestras defensas y viene disfrazado en un formato en el que todavía creemos: las redes sociales y familiares (Heras, 2003). El marketing viral ha sido descrito como "the process of getting customers to pass along a company's marketing message to friends, family and colleagues" (Laudon \& Traver 2001, 381). Cuanto más sencillo sea transformar a un receptor en emisor, mejores resultados se obtienen en la tasa de contagio. La recomendación de un amigo o un familiar otorga credibilidad al mensaje que al mismo tiempo tiene que ser impactante para que el receptor invierta unos segundos de su preciado tiempo y se deje seducir. El autor de la campaña tiene que encontrar las motivaciones del público para crear un contenido que llegue al público sin provocar escepticismo (Domingos, 2005). El elemento clave del marketing viral es la credibilidad. No es la marca sino un conocido quien te recomienda algo, pero si añades el aspecto comercial las personas lo notan y pierde credibilidad. La ventaja que tiene una recomendación de un amigo o de otra fuente de confianza es que posee la credibilidad que le falta a un anuncio (Jurvetson, 2000).

Las herramientas del software social web 2.0 dan la oportunidad a sus usuarios de crear acontecimientos sociales con capacidad para convertirse en noticias en el sentido tradicional. Los propios integrantes de la comunidad son los que propagarán el mensaje, por lo tanto "detectar a aquellos individuos que dentro de la comunidad de marca tengan una actitud abierta, leal y activa con el producto, es esencial para los publicistas para conseguir buenos resultados (...) Se trata de conseguir la identificación total con el mensaje para que éste pueda ser objeto de recomendación" (Ramos, 2007: 216-217). Hay que recuperar la complicidad del consumidor a través de su acción voluntaria, como 
portavoz o conductor, en algunos casos, incluso, como productor de los mensajes. Ese contagio busca dar al mensaje una difusión extraordinaria pudiéndose convertir por su velocidad de propagación y sus efectos en un fenómeno de comunicación. Internet hace posible una propagación rápida y que exista una réplica, una retroalimentación (Del Pino, 2007). En las siguientes líneas mencionamos algunos casos de marketing viral en España, con el objetivo de comprobar cómo esa urgencia por lo inmediato puede conducir a errores y falsedades, centrándonos especialmente en uno concreto: en el fracaso de la campaña de 2010, "estosololoarreglamosentretodos.org", realizada con la técnica conocida como astroturfing.

\section{MENTIRAS DESBOCADAS VERSUS NOTICIAS EN ESPAÑA}

Según el experto en marketing Al Ries, entre las reglas del marketing destaca una por encima de todas: si somos los primeros en lo nuestro, seremos los primeros en la mente de todos. Para ello, según Al Ries, hay que concentrarse en algo, inventar nuestro propio hueco, aunque sea pequeño y ser el primero en llenarlo porque en nuestra memoria sólo hay sitio para los primeros. En 1999, los medios de comunicación daban la noticia sobre una película rodada por tres estudiantes de cinematografía que habían desaparecido sin dejar rastro. Los tres estudiantes habían ido a Maryland para realizar un reportaje y comprobar si era cierta la leyenda sobre una bruja que atormentaba al pueblo. En esto consistió la promoción previa al estreno de The Blair Witch Project, en difundir una falsa historia, en difundir que la grabación era verdadera y no una película y que efectivamente, la película había aparecido pero no había ningún rastro de sus realizadores. Daniel Myrick y Eduardo Sánchez crearon un falso documental rodado cámara en mano que, gracias a esta brillante y entonces muy novedosa campaña viral, se convirtió en un fenómeno que fue más allá de los cines y que, teniendo en cuenta su bajo presupuesto y los casi 250 millones que recaudó en taquilla, la convirtió en una de las cintas más rentables de la historia del cine. Fueron de los primeros en hacer dudar a la audiencia sobre si lo que estaban viendo era un documental con historia real o una ficción. 
En España, un falso grupo musical, llamado The Happiness sacaba al mercado su primer single "Amo a Laura" ${ }^{2}$ en 2006. El videoclip y la canción se difundieron rápidamente gracias a Youtube y Google Video, llegando, incluso, a salir en los medios de comunicación como una noticia más. Además del video apareció una organización llamada "Asociación Nuevo Renacer. Por una juventud sin mácula". Entre sus principios se encontraba la base de toda la campaña viral: "No mires MTV". De este modo, la agencia de publicidad Tiempo BBDO consiguió triplicar la audiencia de MTV España con un grupo musical a favor de la virginidad antes del matrimonio ${ }^{3} .500 .000$ descargas en la red en sólo tres días.

La misma agencia de publicidad protagonizó otra falsa noticia, cuyo embrión era en realidad una campaña publicitaria de la ONGd "Campaña del Milenio". En cuatro minutos de película se observaba a un grupo de cuatro jóvenes entrando en el Congreso y robando la silla del presidente Zapatero. En su lugar, dejaban una nota "Zapatero, el 16 de octubre, en pie contra la pobreza". 41.000 personas vieron el video en los dos primeros días que estuvo en Youtube. Esta vez, la campaña tuvo repercusiones legales. Por un lado, la ONGd tenía el mismo nombre que una acción desarrollada por la ONU en 2000. Concretamente, la Campaña del Milenio de la ONU con 8 objetivos para erradicar a la mitad la pobreza en el mundo para 2015. Desmintieron cualquier relación con esa organización. Por otro lado, algunas de las imágenes se habían rodado dentro del Congreso (el robo del sillón y la grabación de uno de sus pasillos). Los encapuchados

2 http://www.youtube.com/watch?v $=h R d V g \_J A T I I$

3 http://www.marketingdirecto.com/actualidad/anunciantes/la-mtv-y-tiempo-bbdo-estaban-detras-delamo-a-laura/ 
entraron en el Congreso con el permiso de un funcionario y cogieron el sillón de Zapatero ${ }^{4}$.

Sin embargo, parece que la propagación viral de publicidad o campañas institucionales es aceptada por la audiencia si es divertida, impactante (Amo a Laura) o si responde a una causa altruista o asumible al menos por la mayoría (el robo del escaño de Zapatero). En cambio, se está comprobando que lo que no puede hacer una campaña es usurpar la movilización espontánea y veloz que ha venido de la mano de las redes sociales en la web. Un caso paradigmático en España es el fracaso de la campaña estosololoarreglamosentretodos.org, basada en una técnica de comunicación institucional poco conocida y muy arriesgada: el astroturfing

El 25 de febrero de 2010 se presentó en Madrid la campaña “Esto sólo lo arreglamos entre todos", con la intención de aumentar la confianza de los consumidores españoles a través de la exposición de casos reales de superación o creatividad ante la actual crisis económica. La iniciativa partió de Jaime de Andrés, director de publicidad corporativa de Telefónica, y fue promovida por la Fundación Confianza -"entidad sin ánimo de lucro ni filiación política, impulsada y respaldada por las principales empresas y organizaciones del país"-, cuya finalidad es "poner en marcha un proyecto que impulse en la sociedad unos valores, que actúen de palanca para la recuperación de la confianza desaparecida con la crisis" 5 .

Esta fundación está presidida por Javier Gómez Navarro, presidente del Consejo Superior de Cámaras de Comercio y ex ministro socialista, y tiene como portavoces a Antonio Garrigues Walker, presidente de uno de los primeros despachos de abogados de Europa,

${ }^{4}$ Cfr. SOLANAS, I.; ROM, J. Y SABATÉ, J. Un nuevo enfoque para la publicidad y el marketing. La búsqueda de la viralidad. El caso de la campaña “Levántate ZP”, Trípodos, extra, 2007, 995-1.009.

${ }^{5}$ http:/ / fundacionconfianza.es/ 
Guillermo de la Dehesa, economista, presidente del Centro de Investigación de Políticas Económicas de Londres (CEPR) y Miquel Roca i Junyent, padre de la Constitución española. La respaldaron dieciocho grandes empresas españolas ${ }^{6}$ que aportaron entre 150.000 y un millón de euros, completando un presupuesto total de cuatro millones. Es importante tener esto en cuenta, porque ya desde la presentación de los promotores y del presupuesto resulta chocante que quisiera plantearse esta campaña como una movilización social no dirigida.

La apuesta fuerte de esta campaña, diseñada por la agencia de publicidad SCPF, fue la web www.estosololoarreglamosentretodos.org, que además de explicar los porqués y los quiénes, recopila y difunde narraciones y vídeos donde gente anónima y personajes relevantes explican sus ideas para salir de la crisis o su historia de superación personal. También cuenta con un grupo en Facebook (www.facebook.com/estosololoarreglamosentretodos), un canal en Twitter (twitter.com/arreglandoesto) y otro canal en YouTube (www.youtube.com/arreglandoesto). Se trató de una campaña novedosa, no sólo por su intención movilizadora, sin ánimo de lucro, sino también por estar centralizada en los recursos de la web y la web 2.0 con lo que pretendían lograr una propagación viral y por tanto un apoyo popular espontáneo.

Sin embargo, esa supuesta espontaneidad se convirtió en el mayor fracaso de la campaña que, aunque contó con una buena acogida en los medios, donde incluso se cedió espacio a portavoces y participantes para explicar la iniciativa, lo cierto es que, desde el día siguiente, los periódicos recogieron críticas al hecho de que fueran las grandes empresas y personajes cercanos al actual gobierno socialista los que hubieran puesto la campaña en

${ }^{6}$ BBVA, Caja Madrid, Cámara de Comercio, Cepsa, Endesa, El Corte Inglés, Iberdrola, Iberia, Indra, La Caixa, Mapfre, Mercadona, REE, Renfe, Repsol, Santander, SEOPAN y Telefónica. 
marcha. En definitiva, se antojaba como un intento más o menos disimulado de propaganda.

De hecho, lo más significativo es que apenas cinco días después, surgieron unas más que curiosas contracampañas en Facebook y Twitter que, enseguida, superaron en seguidores a la oficial. Así, el 17 de septiembre, la web oficial sumaba 87.933 adhesiones (estosololoarreglamosentretodos.org), mientras que la contra-campaña más fuerte ahora mismo de Facebook -donde se encuentran varias en la misma línea7-, “Esto deberían arreglarlo los que lo jodieron", sumaba 99.794. También la blogosfera y portales como menéame se llenaron pronto de comentarios contrarios a la iniciativa.

Aunque no se presentó como tal, creemos que esta campaña ha sido un intento fallido de aplicar la herramienta de comunicación institucional denominada astroturfing sin prever los riesgos que implica. Parece que fue el senador americano Lloyd Bentsen quien primero acuñó el término "astroturf lobbying" para referirse a un juego de palabras que conjuga la idea de democracia grassroots -intentos espontáneos de canalizar un asunto determinado, patrocinados por personas privadas- en contraposición a los actos nada espontáneos que responden a estrategias de persuasión de políticos, gobiernos, empresas o agencias de relaciones públicas. Astroturf es una conocida marca de césped artificial usada en los Estados Unidos para cubrir los estadios deportivos, así que astroturfing implica imitar la opinión o comportamiento espontáneo de movilización popular. Frente a un activismo llevado a cabo por un nutrido grupo de ciudadanos con escasos fondos, el astroturfing se

7 En los títulos de estos grupos alternativos en Facebook se observa el nivel de enfado y la jocosidad con los que algunas personas recibieron la campaña: “Esto no lo arregla ni su puta madre y menos con vosotros en medio", "Esto sólo lo arreglamos SIN ELLOS", "Esto sólo lo arreglamos entre todos y todas, pero no como ellos quieren", "Esto sólo lo arreglamos con Chuck Norris", "Esto no lo arregla ni McGiver en un Leroy Merlin", o "Esto no lo arregla ni Florentino". 
refiere a un activismo con importantes fondos e impulsado por pocas personas. Así se crea la apariencia de un apoyo popular espontáneo. Si se consigue que aparezca como tal, los beneficios son aún mayores que en el caso del marketing viral, porque incluso la iniciativa parece partir de los propios ciudadanos y estos se sentirán parte de una comunidad con intereses comunes, pero si se descubren los intereses políticos o comerciales, como es el caso con el que finalizamos este artículo, los ciudadanos sentirán que le han usurpado su recién estrenado papel como movilizadores y creadores de redes sociales y volcarán sus esfuerzos en denunciar o boicotear esta ingerencia.

\section{CONCLUSIONES}

El examen de los casos analizados pone de manifiesto cómo las técnicas virales utilizan la velocidad como elemento motor. El principio básico de una pieza viral es su naturaleza escalable, esto es, una propuesta comunicativa de naturaleza persuasiva (conseguir modificar la actitud del receptor) que autogenera un incremento rápido en su difusión, utilizando para ello una red de comunicación determinada. En ese proceso comunicativo hemos de tener en cuenta el uso de fakes de la realidad para contribuir a un mayor impacto y para generar una empatía con los destinatarios que examinan y contemplan el fenómeno viral como si se tratara de un evento de "ficción con tintes de verdad" o de "verdad con tintes de ficción". Finalmente se produce en todas estas manifestaciones un juego de espejos (una "especulación" en sentido etimológico, del latín speculum = imagen, reflejo) que nos presenta y re-presenta la realidad como espectáculo comunicativo. Un falso acontecimiento, una falsa profanación del sillón del presidente Zapatero o un falso lobby. Como si se tratara de una escenificación cinematográfica, similar a la representada en el film de Ronald Emmerich, Independence day, la destrucción de la "White House" por parte de las fuerzas alienígenas se convirtió en el principal reclamo del trailer y un sentimiento de morbo hizo que millones de espectadores fueran a los cines a contemplar la desintegración de uno de los símbolos de Norteamérica. De forma similar, los virales -a 
menor escala de espectacularidad- utilizan el mismo mecanismo de morbosidad para diseñar propuestas visuales semiúrgicas, esto es, piezas donde se produce una manipulación generalizada de los signos bajo el lema de Al Ries: "ser los más rápidos; ser los primeros".

\section{BIBLIOGRAFÍA}

- CASTELLS, Manuel (2006). La sociedad red: Una visión global. Madrid: Alianza.

- DAVENPORT, T. H.; BECK, J. C. (2001). The Attention Economy: Understanding the New Currency of Business. Harvard Business School Press.

- DE MOOIJ, Marieke (2005). Global Marketing and Advertising, Understanding Cultural Paradoxes, $2^{a}$ edición. USA: Sage Publications, Inc.

- DEL PINO, Cristina (2007). "Nueva era en la comunicación comercial audiovisual: el marketing viral". En: Pensar la Publicidad, vol. 1, n 2, p. 63-76.

- DOMINGOS, Pedro (2005). "Mining Social Networks for Viral Marketing". En: IEEE Intelligent Systems, vol. 20, nº 1, p. 80-82.

- GODIN, Seth (2001). Unleashing the Ideavirus. EEUU: Paperback.

- HERAS, Mar (2003). "Márketing viral, el contagio positivo para su negocio". En: Deusto Marketing \& Ventas, no 58, p. 42-45.

- JURVETSON, Steve (2000). “What exactly is viral marketing?". En: Red Herring, ${ }^{\circ}$ 78, p. 110-112.

- LAUDON, Kenneth. C. \& TRAVER, Carol. G. (2001). E-commerce: Business, technology, society. Boston: Addison-Wesley.

- NÚÑEZ, Antonio (2007). ¡Será mejor que lo cuentes! Los relatos como herramientas de comunicación. Storytelling. Barcelona: Empresa Activa.

- RAMOS, Marina (2007). "Comunicación viral y creatividad". En: Creatividad y Sociedad, p. 202-226.

- REICHHELD, Frederick F. (2003). “The one number you need to grow”. En: Harvard Business Review, vol. 81, $\mathrm{n}^{\mathrm{o}}$ 12, p. 47-54. 
- TOURAINE, Alain (2005). Un Nouveau paradigme. París: Librairie Arthème Fayard.

- VIRILIO, Paul (1992). La machine de vision. París: Éditions Galilée.

---. (1993) L'art du motear. París: Éditions Galilée.

---. (1997) Cibermundo, la política de lo peor. Madrid: Cátedra.

---. (1998) La bombe informatique, París: Éditions Galilée. 